\title{
Kil Zeminin Dayanımı Üzerinde Uçucu Kül ve Yüksek Fırın Cürufu Katkılarının Etkisi ve Karşılaştırmalı Analizi
}

\author{
Hakan BİLICİ*, Derviş Volkan OKUR, Murat TÜRKÖZ, Hasan SAVAŞ \\ Eskişehir Osmangazi Üniversitesi, İşaat Mühendisliği Bölümü, Eskişehir \\ (ORCID: 0000-0003-4776-5513) (ORCID: 0000-0002-3416-8202) \\ (ORCID: 0000-0003-0241-113X) (ORCID: 0000-0002-3138-5308)
}

\begin{abstract}
Öz
Bu çalışmada, Eskişehir ilinde kiremit yapımında kullanılan kil zemin numunesinin dayanımı üzerinde atık malzeme olarak da tanımlanan farklı katkı malzemelerinin etkileri karşılaştırmalı olarak incelenmiştir. İyileştirmek için kullanılan katkı malzemelerinin atık olması hem çevre açısından hem mühendislik açısından hem de ekonomik açıdan katkı sağlayacaktır. Bu sebeple kömür kullanılan termik santrallerde atık malzeme olan yüksek firın cürufu (YFC) ve uçucu kül (UK) ile zemin farklı oranlarda karıştırılmıştır. Katkılı serilerde puzolanik reaksiyonu sağlamak amacıyla \%3 oranında kireç sabit tutularak, ilk aşamada \%3, \%6, \%9, \%12, \%15 oranlarında UK ve ikinci aşamada da \%3, \%6, \%9, \%12 oranlarında YFC katkı serilerinde hazırlanan örnekler üzerinde kürsüz (erken dönem), 7 gün ve 28 gün küre bırakılan örnekler üzerinde serbest basınç dayanımı deneyleri yapılmıştır. Bu kapsamda, katkılı çalışmalarda zemin numunesi azaltılarak, azaltıldığı oranda kireç, UK ve YFC katılmış ve böylece toplam karışımın kuru kütlesi sabit tutulmuştur. En yüksek dayanımın \%3 kireç + \%12 UK ve \%3 kireç + $\% 9$ YFC katkısında meydana geldiği tespit edilmiştir. Karşılaştırma yapıldığında, en yüksek dayanımların elde edildiği serilerde kür uygulanmadan yapılan deney sonuçlarında dayanımlarının neredeyse eşit olduğu, kür süresine bağlı olarak ise UK katkısının YFC katkılı serilere oranla serbest basınç dayanımı üzerinde çok daha önemli seviyede dayanım artışına neden olduğu belirlenmiştir.
\end{abstract}

Anahtar kelimeler: Dayanım, uçucu kül, yüksek firın cürufu, kireç.

\section{Comparative Analysis of the Effects of Fly Ash and Blast Furnace Slag Admixtures on the Strength of Clay Soil}

\begin{abstract}
In this study, the effects of different additive materials, also known as waste materials, on the strength of clay soil sample used in tile making in Eskişehir province were investigated comparatively. The waste of the additives used for improvement will contribute to the environment both engineering and economically. For this reason, the soil was mixed with blast furnace slag (BFS) and fly ash (FA) in different proportions. In order to provide pozzolanic reaction in the blended series, 3\% lime is kept constant and in the first stage 3\%, 6\%, 9\%, 12\%, 15\% FA and in the second stage, on $3 \%, 6 \%, 9 \%, 12 \%$ of the samples prepared in the BFS additive series without cure (early period), 7 days and 28 days were left unconfined compressive strength. In this context, the soil sample was reduced by adding lime, FA and BFS to the extent that it was reduced and thus the dry mass of the total mixture was kept constant. The highest strength was found to be $3 \%$ lime $+12 \%$ FA and $3 \%$ lime $+9 \%$ BFS. When the comparison was made, it was determined that in the series where the highest strengths were obtained, their strengths were almost equal in the test results without curing, and depending on the curing time, the FA additive caused a much more significant increase in strength over the unconfined compressive strength compared to the BFS added series.
\end{abstract}

Keywords: Strength, fly ash, slag, lime.

*Sorumlu yazar: hbilici@ogu.edu.tr

Geliş Tarihi: 30.07.2019, Kabul Tarihi: 09.10.2019 


\section{Giriş}

Uçucu kül (UK) ve yüksek firın cürufu (YFC) çimento ikame malzemesidir başka bir deyişle çimento yerine kullanılan atık bir malzemedir. Bu ikame işlemi genellikle betonda çimento miktarını azaltmak için kullanılır. Günümüzde, zeminde dayanım artırmak için derin karıştırma, jet grout vb. yöntemler uygulanır. $\mathrm{Bu}$ yöntemlerle yapılan çalışmalarda genellikle çimento ve/veya çimento şerbeti kullanılmaktadır. Çimento, UK ve YFC'ye göre pahalı bir malzemedir ve atık bir malzeme değildir. UK ve YFC ikame malzemelerinin zeminde dayanım artırmak için kullanılması maliyeti düşürmesinin yanı sıra, atık olan malzemeler kullanıldığı için çevresel olumlu bir etkiye de neden olabilecektir.

Termik santrallerinde oluşan atıkları bertaraf etmek için, uçucu külün yol yapımında ve zemin stabilizasyonunda kullanılması gerektiği günümüzden yaklaşık yarım asır önce öngörülmüşse de, zemin stabilizasyonunda ve yol dolgusunda halen yoğun olarak kullanılmamaktadır [1]. Uygulamada çalışan mühendisler tarafindan yüksek nakliye giderleri nedeniyle UK ve YFC'nin yaygın olarak kullanılmadığı belirtilmektedir. Ülkemizde; uçucu kül, kömürle çalışan 12 adet termik santralden, yüksek fırın curufu ise sadece Ereğli, Karabük ve İskenderun demir çelik fabrikalarından elde edilmektedir [2].

UK Seyitömer (Kütahya) termik santralinden, YFC ise Karabük demir çelik fabrikasından temin edilerek bu çalışmada kullanılmıştır. Kullanılan uçucu külün sınıfı ASTM C 618' göre F sınıfıdır. F sınıfına; $\mathrm{SiO}_{2}+\mathrm{Al}_{2} \mathrm{O}_{3}+\mathrm{Fe}_{2} \mathrm{O}_{3}$ yüzdesi $\% 70$ 'den fazla olan uçucu küller girmektedir. $\mathrm{F}$ sinıfına ait olan uçucu küllerin $\mathrm{CaO}$ oranı \%10'dan düşük olduğu için düşük kireçli olarak da adlandırılırlar [3]. Uçucu Küller, farklı mekanik ve kimyasal özelliklere sahip olmasından dolayı herhangi bir uygulamada kullanılması için tasarım kriterlerinin iyi belinmesi gerekmektedir [4].

UK, kendi başına bağlayılık özelliği olmayan ancak başka bir malzemeyle birleşince bağlayıcılık özelliği kazandığından puzolanik bir malzemedir. Ülkemizde her yıl yaklaşık 15 milyon ton UK santrallerden atık olarak birikmektedir. UK, zararlı maddelerden arındırıldığında inşaattan tarıma kadar bir çok alanda kullanılmaktadır [5]. Uçucu külün fiziksel ve kimyasal özellikleri de dayanıma etkisinde büyük önem arz etmektedir. UK için yürürlükte olan Türk Standartları Tablo 1'de, YFC için yürürlükte olan Türk Standartları Tablo 2'de sunulmaktadır.

Tablo 1. UK için yürürlükte olan Türk Standartları

\begin{tabular}{|c|c|c|}
\hline Standart Adı & Başlık & Kabul Tarihi \\
\hline TS EN 450-1 & $\begin{array}{l}\text { Uçucu kül - Betonda kullanılan- } \\
\text { Bölüm 1: Tarif, özellikler ve uygunluk kriterleri }\end{array}$ & $10 / 04 / 2013$ \\
\hline TS EN 450-2 & $\begin{array}{l}\text { Uçucu kül - Betonda kullanılan- } \\
\text { Bölüm 2: Uygunluk değerlendirmesi }\end{array}$ & 20.03 .2008 \\
\hline TS EN 451-1 & $\begin{array}{l}\text { Uçucu kül - Deney yöntemleri - } \\
\text { Bölüm 1: Serbest kalsiyum oksit muhtevasının tayini }\end{array}$ & $18 / 12 / 2017$ \\
\hline TS EN 451-2 & $\begin{array}{l}\text { Uçucu kül - Deney yöntemleri - } \\
\text { Bölüm 2: Islak eleme ile incelik tayini }\end{array}$ & $18 / 12 / 2017$ \\
\hline $\begin{array}{l}\text { TSE CEN / TR } \\
16443: 2013\end{array}$ & $\begin{array}{l}\text { EN 450-1:2005 + A1 revizyonu için tarihçe : } \\
2007 \text { - Beton için uçucu kül }\end{array}$ & $12 / 06 / 2013$ \\
\hline $\begin{array}{l}\text { TSE CEN / TR } \\
15840\end{array}$ & Betonda kullanılan uçucu külün uygunluk değerlendirmesi & $09 / 10 / 2013$ \\
\hline TS EN 14227-3 & $\begin{array}{l}\text { Hidrolik bağlayıcılı karışımlar - Özellikler - } \\
\text { Bölüm 3: Uçucu kül bağlayıcılı karışımlar }\end{array}$ & $18 / 12 / 2013$ \\
\hline TS EN 14227-4 & $\begin{array}{l}\text { Hidrolik bağlayıcılı karışımlar - Özellikler - } \\
\text { Bölüm 4: Hidrolik bağlayıcılı karışımlar için uçucu kül }\end{array}$ & $18 / 12 / 2013$ \\
\hline
\end{tabular}

UK ilavesi zeminin şişme potansiyelini azalttı̆̆ daha önce yapılan çalışmalarda tespit edilmiştir. Bu azalmanın uçucu külün, zemin tanecikleriyle etkileşimi sonrasında oluşturduğu bağlardan kaynaklandığı öne sürülmektedir. Şişme potansiyeli, yaklaşı \%14 olan bir kil zeminin, uçucu kül katkısıyla \% 0.8'e düştüğü belirlenmiştir [6]. Uçucu küllerin geçirgenliği azaltıcı etkisi olduğundan, zararlı atık ve çöp depolanan alanlarda ve katı atık tesislerinde geçirimsiz bir perde elde etmek amacıyla kullanılabilmektedir [7]. Düşük plastisiteli gri Tayvan kiline puzolanik reaksiyon elde edebilmek amacıyla kireç içeren YFC katılarak yapılan çalışmalarda, UK oranı sabit tutulmuş ve YFC oranı arttıkça permeabilite katsayısının düştüğü dolayısıyla geçirimliliğin azaldığı gözlemlenmiştir [8]. 
Tablo 2. YFC için yürürlükte olan Türk Standartları

\begin{tabular}{|c|l|c|}
\hline Standart Adı & \multicolumn{1}{|c|}{ Başılık } & Kabul Tarihi \\
\hline TS EN 13286-44 & $\begin{array}{l}\text { Bağlayıcısız veya hidrolik bağlayıılı karışımlar - Deney yöntemleri - } \\
\text { Bölüm 44: Vitrifiye yüksek firın cürufunun alfa katsayısının tayini }\end{array}$ & $28 / 01 / 2004$ \\
\hline TS EN 14227-2 & $\begin{array}{l}\text { Hidrolik bağlayıcılı karışımlar - Özellikler - } \\
\text { Bölüm 2 : Cüruf Bağlayıcılı Karışımlar }\end{array}$ & $18 / 12 / 2013$ \\
\hline
\end{tabular}

Yüksek şişme potansiyeline sahip olduğu bilinen Hawai Kiline, UK ve kireç eklenerek şişme potansiyelinde azalma, sıkışma özeliklerinde iyileşme ve Kaliforniya Taşıma Oranı (CBR) değerinde artış olduğu gözlemlenmiştir [9]. Uçucu küllerin; zemin stabilizasyonunda, katı atık sahalarında, taban ve örtü tabakalarında kullanılabileceği ve katkı olarak kullanılmasının kilin kayma direncinde önemli artışlar meydana getirdiği ifade edilmiştir [10]. Soma uçucu külü üzerinde yapılan çalışmalarda, uçucu külün katkısız halinin tek başına atık depolama alanlarında geçirimsizlik perdeleri için istenen permeabilite katsayısı değerini sağlamadığı ancak kireç, çimento ve bentonit katkısıyla ulaşmasının mümkün olduğu belirlenmiştir. Bu durum da, uçucu külün katkı olarak kullanılmasında özelliklerinin önemini göstermektedir [11].

UK katkılı zeminlerde kür süresi artıkça dayanım artmaktadır. Artan dayanımın sebebi, hem kohezyon hemde kayma direnci açısındaki artıştan dolayı oluşmaktadır. Kohezyon artışı, uçucu külün çimentolaşma özelliğine, kayma direnci açısındaki artışın sebebi ise uçucu kül taneciklerinin küresel yapısına bağlı olmaktadır [12]. UK katkısının maksimum kuru birim hacim ağırlığını düşürdüğü, optimum su muhtevasını artırdığı, likit limit ve plastik limit değerini artırdığı, plastisite indisini düşürdüğü, içsel sürtünme açısı ve kohezyonda artış meydana getirdiği, boşluk oranını azalttığı belirlenmiştir[13]. Kireç ve UK oranı sabit tutulup (\%15), farklı oranlarda (\%10,\%15,\%20) granit atığ1 (polisaj) ilave edilerek hazırlanan yapay kaolen kili numunelerinin mukavemet ve CBR değerleri katkısız kaoline göre daha yüksek olmuştur [14].

Çimento ve UK katkılı çalışmalarda kür süresinin kısa olmasının malzeme özelliğinin ölçülmesi için doğru yöntem olmadığı, UK gibi katkılarla zemin iyileştirilmesi yapılırken en az 4 hafta (28 gün) kür süresinin beklenmesi ve bu süreden sonra dayanımlarının ölçülmesi ve davranışlarının gözlemlenmesi gerekmektedir [15].

Dispersif ve şişme potansiyeli olan düşük plastisiteli kil numuneler üzerinde farklı oranlarda Çatalağzı(F sınıfi) ve Soma(C sınıfı) uçucu külleri katkısı ie yapılan çalışmalar neticesinde, her iki katkı malzemesinin de şişme potansiyelini azalttığı, Soma uçucu külünün Çatalağzı uçucu külüne oranla şişme ve dayanım karakteristiklerine daha fazla olumlu etki yaptığı, Soma uçucu külü katkısının dispersif davranışa olumlu yönde etkisi olurken Çatalağzı uçucu külünün dispersif davranışa etkisi olmamıştır [16]. Killi kum olan Eskişehir meşelik zeminine farklı oranlarda (\%5, \%10, \%15, \%20, \%25, $\% 30, \% 35$ ) uçucu kül katkısı, kuru birim hacim ağırlığını düşürürken, optimum su muhtevası ve serbest basınç dayanımını artırmıştır [17].

Dispersif zeminler için \%10 uçucu kül katkısının etkili iyileştirme için ideal olduğu, dayanımın artırılması için her iki sınıf (F ve C sınıfı) uçucu kül kullanılabilmektedir. Fakat aynı katkı seviyelerinde C sınıfı uçucu külün zeminde daha yüksek dayanıma sahiptir. Dispersif zeminlerin stabilizasyonu için F sınıfı uçucu külün tek başına kullanılmaması, farklı bir katkı maddesi ilavesiyle kullanılması gerektiği belirtilmiştir [18].

YFC'nin, geoteknik özelliklerinden olan özgül yoğunluk, maksimum kuru birim hacim ağırlık, içsel sürtünme açısı, hidrolik iletkenlik, $\mathrm{pH}$ ve CBR değerleri farklılıklar gösterebilmektedir. Farklı YFC'ye ait özgül yoğunluk değerleri 2.41 ve 2.67, pH değeri 12 ve kuru birim hacim ağırlıkları 1.34 ve $1.47 \mathrm{Mg} / \mathrm{m}^{3}$, içsel sürtünme açıları $39^{\circ}$ ve $40^{\circ}$, hidrolik iletkenlikleri $1.8 \times 10^{-3}$ ve $3.4 \times 10^{-3} \mathrm{~m} / \mathrm{s}$, CBR değerleri ise \%16 ve \%31.1 olarak tespit edilmiştir [19]. Şişen zeminlerin iyileştirilmesinde ögütülmüş YFC ile çimento karışımı ve öğütülmüş YFC katkısında, katkı oranı arttıkça kil ve silt yüzdesi, plastisite indisi ve şişme yüzdesi azalırken, özgül yoğunluk artmaktadır. YFC ile çimento karışımının hem çevresel hemde şişme yüzdesi açısından en etkili yüzde oranı \%15 olmaktadır [20].

Kil bir zeminin kıvam limitleri üzerindeki etkisine cüruf ve uçucu kül katkısının zamana bağlı değişimini incelendiğinde, UK ve YFC'nin 30 günlük süreç değişiminde killerin kıvam limitlerinde önemli bir değişiklik meydana getirmedikleri tespit edilmiştir [21].

Killi zeminlerin iyileştirilmesinde kireç ve yüksek firın curufunun etkileşimini araştırıldığında, YFC kireç ile karıştırıldığında plastisiteyi düşürmekte, tek başına bir etkisi bulunmamaktadır. YFC tek 
başına kullanıldığında serbest basınç dayanımını 2 kat artırırken, \%5 kireç + \%3.33 YFC katkılı karışımı serbest basınç dayanımını 11 kat artırmaktadır [22].

Kum - bentonit karışımlarının kireç ve YFC ile iyileştirilmesi üzerine yapılan çalışmalarda kum ile karıştırılacak en uygun bentonit oranının \%50 Kum - \%50 Bentonit olduğu, bu karışıma karıştırılacak kireç ve YFC katkısının kum-bentonit karışımlarının mukavemet ve geçirimlilik özelliklerini olumlu yönde etkilediği anlaşılmıştır [23].

Kolsuz kili ve bentonit kil zeminlerine farklı oranlarda(\%5, \%10, \%20, \%25, \%30 ve \%50) yüksek firın cürufu katkısı ekleyerek, yüksek firın cürufunun kil zeminlerin stabilizasyonundaki etkisi araştırıldığında, her iki zeminde de yüksek fırın cürufu oranı arttıkça birim hacim ağırlı̆̆ının artmakta, Kolsuz kilinde plastik limiti artmakta, likit limiti $\% 21-\% 28$ aralı̆ğnda azalmakta, bentonit kilinde plastik limit \%32-\%55 aralığında artarken likit limit \%147-\%212 aralığında azalmaktadır [24].

Yüksek firın curufunun hemen kullanılmasının (taze) ve bekletilmesinin (yıllanmış) etkisini araştırmak için kompaksiyon ve büyük ölçekli kesme kutusu deneyi gerçekleştirildiğinde, iki numune arasında özgül yoğunluk değerleri hemen hemen eşit olmakta, yıllanmış yüksek firın curufunda; ince oranının azalmakta, optimum su muhtevası ve kuru birim hacim ağırlıkları daha yüksek olmakta ve içsel sürtünme açısının daha düşük olmaktadır [25].

Modifiye proktor enerjisi ile sıkıştırılan YFC numunelerinin standart proctor enerjisi ile sıkıştırılan numunelerden 2 kattan daha yüksek CBR değerine sahip olduğu, ince daneli numunelerin iri daneli numunelerden daha yüksek taşıma kapasitesine sahip olduğu, deniz suyu ile hazırlanan numunelerin musluk suyu ile hazırlanan numunelere kıyasla CBR değerinin $\% 17$ daha yüksek olduğu ve YFC'nin dolgu malzemesi olarak kullanılabileceği tespit edilmiştir [26].

\section{Materyal ve Metot}

Çalışmada kullanılan zemin örneğini tanımlamak için, elek analizi, hidrometri analizi (ASTM D 422 63), kıvam limitleri (ASTM D 4318-00) ve özgül gravite (ASTM D 854-00) deneyleri yapılmıştır. Numunelerin hazırlanmasında ve deney aşamasında ilgili standart yöntemlere uyulmuştur (ASTM, 1994). Zemin örneğinin tamamı ince daneli zeminden oluşmaktadır. Kıvam limitleri sonucu $L L=\% 35$, $\mathrm{PL}=\% 22$ ve $\mathrm{PI}=\% 13$ olarak bulunmuş ve Birleştirilmiş Zemin Sınıflandırma Sistemine (USCS) göre zemin örneği CL (Düşük Plastisiteli Kil) olarak sınıflandırılmıştır (ASTM D 2487-00).

Çalışmada katkı olarak kullanılan kireç, piyasada 50 kg'llk torbalar halinde satılan söndürülmüş toz kireçtir. Kirecin organik madde miktarı \% 0,5 özgül agırlı̆̆ $2,3 \mathrm{gr} / \mathrm{cm}^{3}{ }^{3}$ tür. Kirece ait karakteristik özellikler Tablo 3'de verilmiştir. ASTM C 977-10 standartında zemin stablizasyonunda zemine katk1 olarak kullanılan kirecin sahip olması gereken özellikler verilmektedir. Kullanılan kireç katkısının söz konusu standarta göre stabilizasyonda kullanımı uygundur.

Tablo 3. Kullanılan kirecin karakteristik özellikleri

\begin{tabular}{|c|c|c|c|}
\hline Özellik Adı & Değeri & Özellik Adı & Değeri \\
\hline Fiziki Görünüş & Kuru Toz Beyaz & $(>63 \mu \mathrm{m}),(\%)$ & $7-10$ \\
\hline Kaynama Derecesi, $\left({ }^{\circ} \mathrm{C}\right)$ & 100 & $\mathrm{Ca}(\mathrm{OH})_{2},(\%)$ & $80-86$ \\
\hline Ergime Derecesi, $\left({ }^{\circ} \mathrm{C}\right)$ & 580 & $\mathrm{CaO}+\mathrm{MgO},(\%)$ & $90-93$ \\
\hline Yoğunluk, $\left(\mathrm{kg} / \mathrm{m}^{3}\right)$ & Maksimum 500 & $\mathrm{~S}$ inırlı $\mathrm{H}_{2} \mathrm{O}$ & $19.4-20.85$ \\
\hline Özgül ağırlık $\left(\mathrm{gr} / \mathrm{cm}^{3}\right)$ & $1.2-1.5$ & $\mathrm{~S}$ & Maksimum 0.5 \\
\hline$(>90 \mu \mathrm{m}),(\%)$ & $3-6$ & $\mathrm{pH},\left(25^{\circ} \mathrm{C}\right)$ & 12.4 \\
\hline
\end{tabular}

Çalışmada kullanılan UK'nin; kimyasal özellikleri Tablo 4'de, fiziksel özellikleri Tablo 5'de ve taramalı elektro mikroskobu (SEM) altında görüntüsü Şekil 1'de sunulmaktadır. Çalışmada kullanılan YFC örneğini tanımlamak için, elek analizi ve özgül gravite deneyleri yapılmıştır. Numunelerin hazırlanmasında ve deney aşamasında ilgili standart yöntemlere uyulmuştur ( ASTM, 1994). Tanımlama deneyleri neticesinde; Çak1l $=\% 55,3, \mathrm{Kum}=\% 40$ ve İnce $($ Kil + Silt $)=\% 4.7, \mathrm{D}_{60}=6.75, \mathrm{D}_{30}=1.90, \mathrm{D}_{30}$ $=0.25, \mathrm{C}_{\mathrm{u}}=3.55, \mathrm{C}_{\mathrm{u}}=2.14, \mathrm{Gs}=2.76$ bulunmuş ve Birleştirilmiş Zemin Sınıflandırma Sistemine (USCS) göre YFC katkısı GP (Kötü Derecelenmiş Çakı1) olarak sınıflandırılmıştır (ASTM D 2487-00). Bu 
çalışmada YFC'nin; 4 nolu (4.75 mm) elekten geçen kısmı kullanılmış ve fiziksel özellikleri Tablo 6' da, kimyasal özellikleri Tablo $7^{`}$ de, taramalı elektro mikroskobu (SEM) altında görüntüsü Şekil 2’de ve XRD grafiği Şekil 3'de sunulmaktadır.

Tablo 4. Çalı̧̧mada kullanılan uçucu külün kimyasal özellikleri

\begin{tabular}{|c|c|c|c|c|c|}
\hline Bileşik & $(\%)$ & Bileșik & $(\%)$ & Bileşik & $($ \%) \\
\hline $\mathrm{SiO}_{2}$ & 55.36 & $\mathrm{MgO}$ & 5.40 & $\mathrm{~K}_{2} \mathrm{O}$ & 0.80 \\
\hline $\mathrm{Al}_{2} \mathrm{O}_{3}$ & 18.34 & $\mathrm{CaO}$ & 4.50 & $\mathrm{TiO}_{2}$ & 0.43 \\
\hline $\mathrm{Fe}_{2} \mathrm{O}_{3}$ & 9.81 & $\mathrm{Na}_{2} \mathrm{O}$ & 0.12 & $\mathrm{SO}_{3}$ & 1.51 \\
\hline
\end{tabular}

Tablo 5. Kullanılan uçucu külün (UK) fiziksel özellikleri

\begin{tabular}{|l|c|}
\hline Özgül gravite(Gs) & 1.76 \\
\hline Dane büyüklüğü analizi (\%) (kum/silt/kil) & $0 / 83 / 17$ \\
\hline Likit limit(LL),\% & 55 \\
\hline Plastik limit(PL), \% & 26 \\
\hline Plastisite indisi(PI), \% & 29 \\
\hline Optimum su muhtevasi $\left(\mathrm{w}_{\text {opt }}\right) \%$ & 38 \\
\hline Maksimum kuru yoğunluk $\left(\mathbf{\rho d}_{\max }\right)\left(\mathrm{Mg} / \mathrm{m}^{3}\right)$ & 1.23 \\
\hline
\end{tabular}

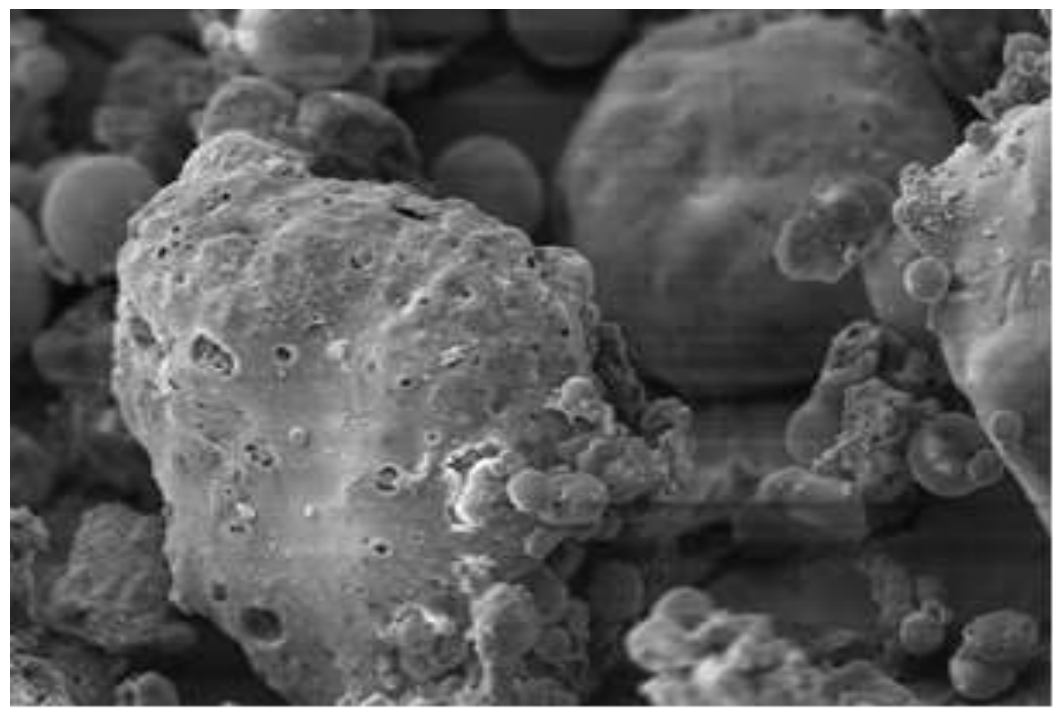

Şekil 1. Kullanılan uçucu külün (UK) SEM fotoğrafi

Tablo 6. Kullanılan yüksek firın cürufun (YFC) fiziksel özellikleri

\begin{tabular}{|l|c|}
\hline Los Angeles Aşınma (ASTM C131), (\%) & $20-25$ \\
\hline Hava tesirlerine karşı dayanıklılık deneyi (ASTM C88), (\%) & $<12$ \\
\hline İcsel Sürtünme Açı1 $\left({ }^{\circ}\right)$ & $40-50$ \\
\hline Sertlik (Mohr Skalası) & $6-7$ \\
\hline Yassılık İndeksi, (\%) & 15.5 \\
\hline Su emme Oranı, (\%) & $0.95-0.83$ \\
\hline
\end{tabular}

Tablo 7. Çalışmada kullanılan yüksek firın cürufun (YFC) kimyasal özellikleri

\begin{tabular}{|c|c|c|c|}
\hline Bileşik & $(\boldsymbol{\%})$ & Bileşik & $(\boldsymbol{\%})$ \\
\hline $\mathrm{CaO}$ & $47-55$ & Toplam Mn & $3.5-5.3$ \\
\hline $\mathrm{SiO}_{2}$ & $57.5-15$ & $\mathrm{Al}_{2} \mathrm{O}_{3}$ & $1.2-1.7$ \\
\hline Toplam Fe & $20-26$ & $\mathrm{MgO}$ & $1.3-1.5$ \\
\hline $\mathrm{Serbest} \mathrm{CaO}$ & 6.5 & $\mathrm{Na}_{2} \mathrm{O}$ & - \\
\hline $\mathrm{Cao} / \mathrm{SiO} 2$ & $3.7-6.25$ & $\mathrm{~S}$ & - \\
\hline
\end{tabular}




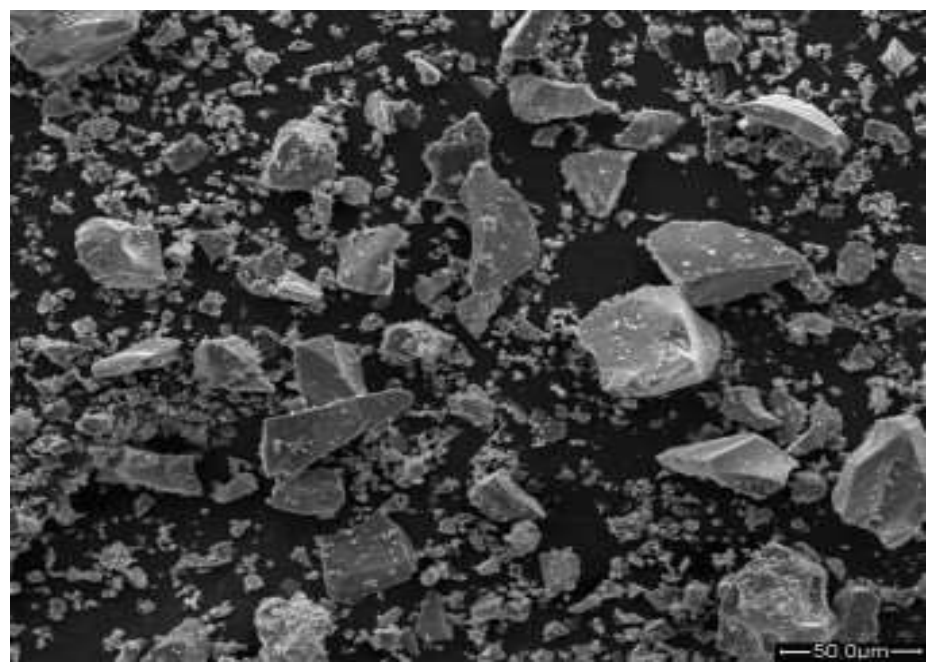

Şekil 2. Kullanılan yüksek firın cürufun (YFC) SEM fotoğrafi

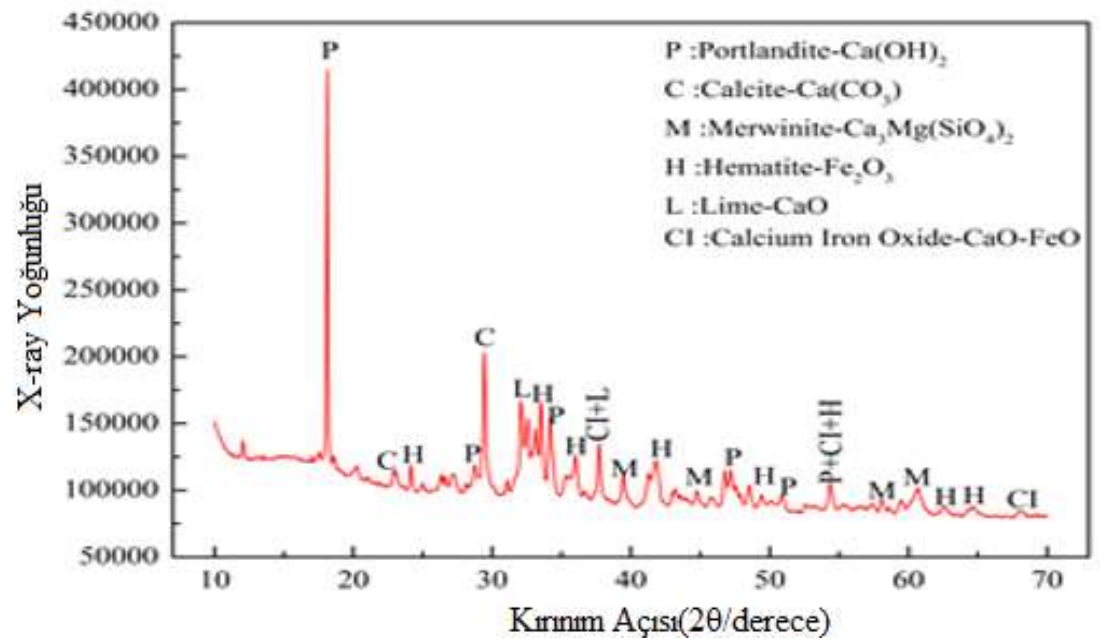

Şekil 3. Kullanılan yüksek firın cürufun (YFC) XRD grafiği

Katkı1ı örneklerin dayanım özelliklerinin değerlendirilmesi için serbest basınç dayanımı deneyleri yapılmıştır. Serbest basınç deneyi, zeminlerin drenajsız kayma dayanımının belirlenmesinde en yaygın kullanılan yöntemdir. Drenaj koşullarının kontrol edilememesi nedeniyle, kayma dayanımının hızlı yükleme yapılarak elde edildiği varsayılmaktadır. Örnekler, yüksekliklerinin çaplarına oranı 2 (100 mm yükseklik ve $50 \mathrm{~mm}$ çap) olan paslanmaz çelik tüpler içinde her bir katkı serisi için belirlenen özelliklerde sıkıştırılarak hazırlanmıştır. Tüplerden çıkartılan örnekler streç filmlere sarılarak vakumlu desikatörlerde 7 ve 28 gün boyunca küre bırakılmıştır. Bu prosedür, hem katkı içeriğinin hem de kürlenme süresinin, numunelerin dayanımı üzerindeki etkilerinin belirlenmesini sağlamıştır. Farklı kür sürelerine maruz bırakılan katkılı örnekler üzerinde serbest basınç deneyleri yükleme hızı $1 \mathrm{~mm} /$ dak olacak şekilde yapılmıştır.

\section{Bulgular ve Tartışma}

Son yıllarda, killi zeminlerin mühendislik özelliklerini geliştirmek için sık sık endüstriyel yan ürünler kullanılmaktadır. Stabilizasyon amacıyla uçucu kül, yüksek fırın cürufu ve silika dumanı gibi katkı maddelerinin kullanılması, hem çevreci hem de ekonomik faydalar sağlamaktadır. İlaveten, bu katkı maddelerinin kireçle birlikte kullanılması stabilizasyonun verimliliğini önemli ölçüde artırmaktadır. Zemin numunesi üzerinde yapılan tanımlama deneyleri sonucunda zeminin CL (Düşük Plastisiteli Kil) olup, Standart Proctor Kompaksiyon deneyi sonucunda elde edilen kompaksiyon karakteristikleri $\mathrm{W}_{\mathrm{op}}=\% 17$ ve $\boldsymbol{\rho}_{\mathrm{dmax}}=1.71 \mathrm{Mg} / \mathrm{m}^{3}$ ve özgül gravite değeri de (Gs) 2.72 olarak belirlenmiştir. Standart Proctor enerji seviyesinde hazırlanan katkısız örnekler üzerinde kür uygulanmadan yapılan serbest 
basınç deneyinde ortalama serbest basınç dayanımları $108 \mathrm{kPa}$ bulunmuştur. Buna göre kohezyon değeri yaklaşık olarak $54 \mathrm{kPa}$ 'dır.

Çalışmada kullanılan kil zemine, hem daha iyi işlenebilirlik hem de puzolaonik reaksiyonu hızlandırmak için $\% 3$ oranında sabit tutulan kireç katkısına ilave farklı yüzdelerde UK (\%3, \%6, \%9, $\% 12, \% 15)$ ve YFC (\%3, \%6, \%9, \%12) katk1larıyla kür uygulanmadan (erken dönem), 7 gün ve 28 gün küre maruz bırakılan örnekler üzerinde serbest basınç dayanımı deneyleri yapılmış ve elde edilen sonuçlar karşılaştırmalı olarak değerlendirilmiştir. Bu kapsamda, katkılı serilerde zemin numunesi azaltılarak, azaltıldığı oranda kireç, UK ve YFC katılmış ve böylece toplam karışımın kuru kütlesi sabit tutulmuştur. UK katkısının, katkı oranı ve kür süresiyle serbest basınç dayanımındaki değişim Şekil 4'de, YFC katkısının, katkı oranı ve kür süresiyle serbest basınç dayanımındaki değişim ise Şekil 5'de sunulmuştur.

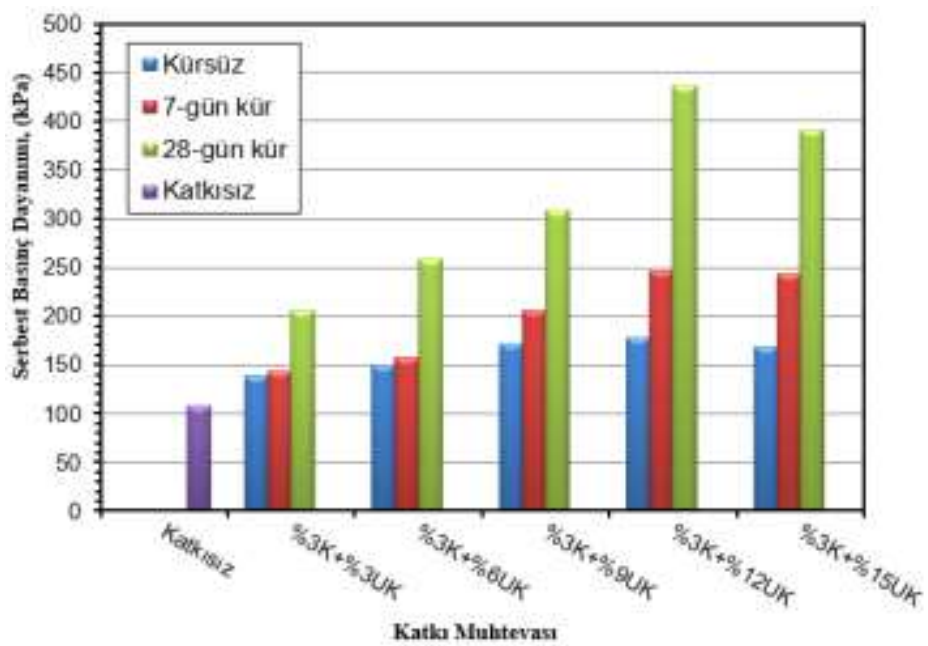

Şekil 4. Serbest basınç dayanımının UK katkısı ile değişimi

Şekil 4'te görülebileceği gibi, kürsüz durumda numunelerin serbest basınç dayanımı (SBD) değerlerinde önemli bir değişiklik olmamıştır. Kür süresi arttıkça dayanımda önemli artışlar gözlenmiştir. SBD deney sonuçlarından, UK içeriği\% 3'ten 12'e çıkarıldığında, UK katkılı numunelerin SBD değerleri sırasıyla 7 ve 28 kürleme günü için sırasıyla $143 \mathrm{kPa}$ 'dan $247 \mathrm{kPa}$ 'ya ve $205 \mathrm{kPa}$ 'dan 436 kPa'ya yükselmiştir. 28 gün kür sonrası elde edilen dayanım değerleri 7 gün küre bırakılan örneklerin dayanım değerlerine oranla daha büyük olmuştur. \% 12'den fazla UK katkısı, dayanım değerlerinde bir azalmaya yol açmıştır. Zeminin ince malzeme içeriğinin düşük olduğu düşünülürse, $\% 12$ 'dan fazla UK zemindeki kil ile yeterince reaksiyona girememiştir.

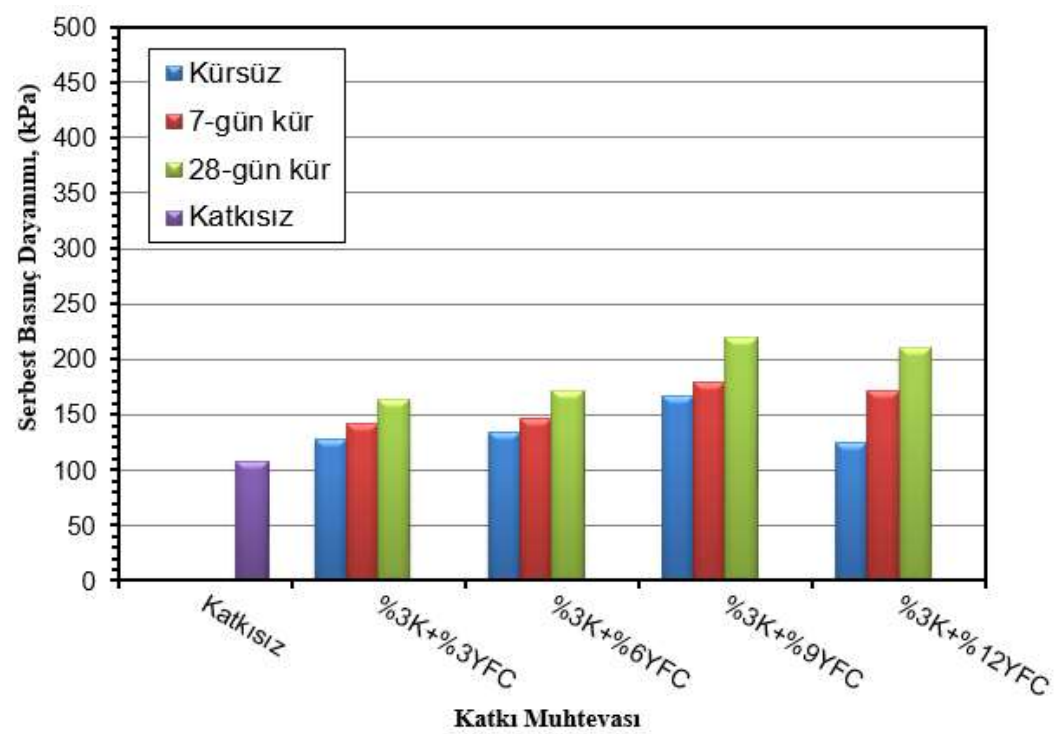

Şekil 5. Serbest basınç dayanımının YFC katkısı ile değişimi 
YFC'un etkisinin değerlendirildiği Şekil 5'ten, hem kür süresinin hem de artan YFC katk1 yüzdesinin dayanım üzerindeki etkisinin UK katkılı seriler kadar etkili olmadığı görülmektedir. Özellikle \%3K+ \%9 YCF katk1 seviyesinden daha yüksek YFC katkı seviyesinde kürsüz dayanımda azalma olmuştur.

En yüksek dayanımın UK kullanılarak $\% 3 \mathrm{~K}+\% 12$ UK katkısıyla, YFC kullanılmasında ise $\% 3 \mathrm{~K}+\% 9$ YFC katkısında meydana geldiği tespit edilmiştir. En yüksek dayanım elde edilen UK ( \%3 Kireç +\%12 UK) ve YFC( \%3 Kireç + \%9 YFC) katkı oranlarıla hazırlanan zeminlerin serbest basınç dayanımının katkısız zeminin serbest basınç dayanımına oranının kür süresini ile değişimini gösteren grafik Şekil 6'da sunulmaktadır. Karşılaştırma yapıldığında, en yüksek dayanımların elde edildiği oranlarda karışım hazırlandığında kür uygulanmadan (erken dönem dayanımlarında) dayanımlarının neredeyse eşit olduğu, uzun vadede ise uçucu kül katkısının neredeyse iki katı oranında serbest basınç dayanımı oluşturduğu sonucuna varıldığı belirlenmiştir. Bu durumun nedeni uçucu külün, yüksek firın cürufu ile karşılaştırıldığında daha yüksek puzolanik özelliğe sahip olmasıdır. Stabilizasyon, katyon değişimi, flokülasyon, aglomerasyon, karbonasyon ve puzolanik reaksiyonla sağlanır [27-29].

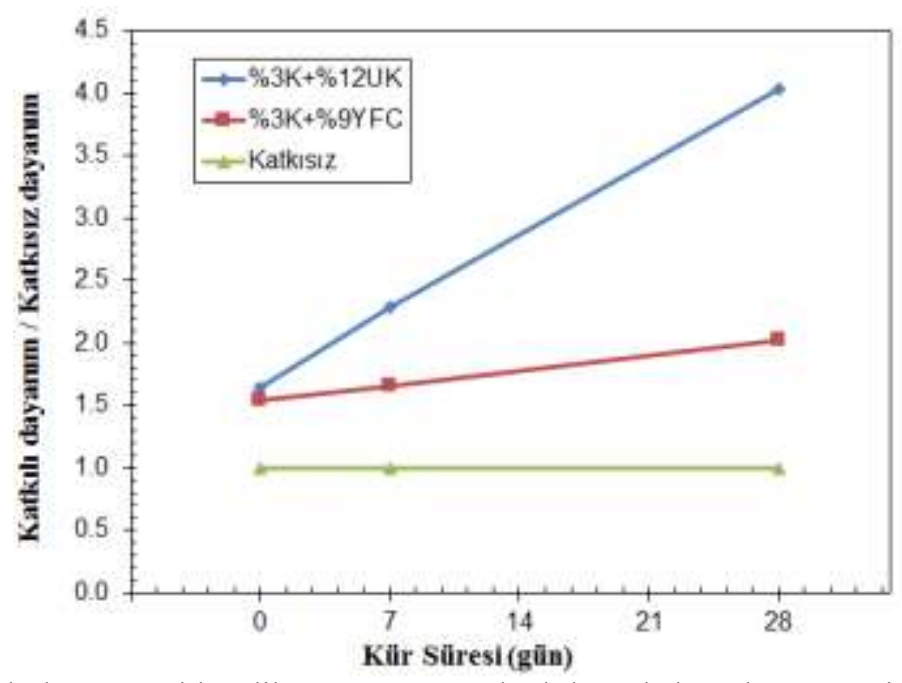

Şekil 5. En yüksek dayanım elde edilen UK ve YFC katkılarında hazırlanan zeminlerin serbest basınç dayanımının katkısız zeminin serbest basınç dayanımına oranının kür süresini ile değişimi

Zeminlerin arazide maruz kaldığı yükleri ve bu yüklere karşı gösterdikleri davranışları, eşit koşullarda belirlemek ve arazi koşullarını modellemek laboratuvarda yapılan deneylerin asıl amacıdır [30]. Zeminlerin olumsuz yönlerini en uygun maliyetle iyileştirmenin ilk aşaması zeminlerin davranışının bilinmesidir. Bu da ancak laboratuvar deneyleri ile mümkündür.

\section{Sonuç ve Öneriler}

Her türlü zeminin mekanik ve/veya dinamik özelliklerinin bilinerek, olumsuz özelliklerinin sslah edilmesi, üzerine yapılacak yapı ve yapıyı kullanacak canlılar açısından güven ve önem arz etmektedir. Zeminler ister dolgu olarak, ister yapı altında taşıyıcı olarak kullanılsın, yapı güvenliği açısından en önemli malzemedir. Bu çalışmada atık malzeme ve çevreye zararı bulunan malzemelerden olan UK ve YFC'nin uygun oranlarda katkı olarak karıştırılması zeminin dayanım özelliklerini artırdığı tespit edilmiştir. UK ve YFC'nin dolgularda kullanılması ile alt temel ve temel tabakalarında kullanılan agreganın ocaktan çıkarılması, parçalanması, patlatma yapılması gibi doğaya zarar verecek unsurları azaltacak, aynı zamanda agrega temini için kullanılan benzin ve motorlu iş makinelerinin doğaya $\mathrm{CO}$ salınımını azaltacak, hava kirlenmesine ve maliyet tasarrufuna yol açacaktır. Zeminin sslah edilmesi doğada atık olarak kullanılan malzemelerle gerçekleştirilirse, bu durum çevresel olumlu bir etkiye de yol açacaktır. Böylece; bu malzemelerin kullanımı ile hem çevresel bir sorun oluşturması engellenirken hem de ekonomiye ve zemin dayanımına da katkı sağladı̆̆ı görülmektedir. 


\section{Yazarların Katkısı}

Çalışmada tüm yazarlar eşit oranda katkı sunmuştur.

\section{Çıkar Çatışması Beyanı}

Yazarlar arasında herhangi bir çıkar çatışması bulunmamaktadır.

\section{Araştırma ve Yayın Etiği Beyanı}

Yapılan çalışmada araştırma ve yayın etiğine uyulmuştur.

\section{Kaynaklar}

[1] Seals R.K. 1973. Properties of Bottom Ash/boiler Slag and Fly Ash. Short Course. Technology and Utilization of Power Plant Ash, 59s.

[2] ÇİMSA. 2012. Mineral Katkılar-Uçucu Kül. Çimento Araştırma ve Uygulama Merkezi, 8-11.

[3] Türker P., Erdoğan B., Katnaş F., Yeğinobalı A. 2009. Türkiye'deki Uçucu Küllerin Sınıflandırması ve Özellikleri, TÇMB.

[4] Tosun H. 1999. Sulama Kanallarında Görülen Şişen Zemin Problemleri ve İnşaat Önlemleri. Osmangazi Üniversitesi Mühendislik Mimarlık Fakültesi Dergisi, 12 (1): 23-24.

[5] Güler G., Güler E., İpekoğlu Ü., Mordoğan H. 2005. Uçucu Küllerin Özellikleri ve Kullanım Alanlar1. Türkiye 19. Uluslararası Madencilik Kongresi ve Fuar1, IMCET2005, İzmir.

[6] Ferguson G. 1993. Use of Self-cementing Fly Ash as a Soil Stabilization Agent: Fly Ash for Soil Improvement. Geotechnical Special Publication, 36: 1-15.

[7] Wasti Y. 1993. Uçucu Küllerin Geoteknik Uygulamalarda Kullanımı. Endüstriyel Atıkların İnşaat Sektöründe Kullanılması Sempozyumu, TMMOB İnşaat Mühendisleri Odası Ankara Şubesi, Ankara.

[8] Chu S.C., Kao H.S. 1993. A study of Engineering Properties of a Clay Modified by Fly Ash and Slag: Fly Ash for Soil Improvement. Geotechnical Special Publication, 36: 89-100.

[9] Nicholson P.O., Kashyap V. 1993. Fly ash Stabilization of Tropic Hawaiian Soils. Fly Ash for Soil Improvement, Geotechnical Special Publication, 36: 15-30.

[10] Tan O., İyisan R. 1996. Uçucu Kül ile Zemin Stabilizasyonu. ZMTM 6. Ulusal Kongresi, Dokuz Eylül Üniversitesi, 417-426.

[11] Çokca E. 1997. Frost Susceptibility Properties of Soma-B Fly Ash. Jorurnal of Energy Engineering, 123 (1): 1-10.

[12] Çakır M. 1999. Uçucu Kül ile Zemin Stabilizasyonu. Yüksek Lisans Tezi, İstanbul Teknik Üniversitesi Fen Bilimleri Enstitüsü, İstanbul.

[13] Aytekin S. 2009. Uçucu Küllerin Zeminlerin Islahında Kullanımı. Yüksek Lisans Tezi, Çukurova Üniversitesi Fen Bilimleri Enstitüsü, Adana.

[14] Öntürk K. 2011. Zemin İyileştirmesinde Polisaj, Kireç ve Uçucu Külün Kullanımı. Yüksek Lisans Tezi, Sakarya Üniversitesi Fen Bilimleri Enstitüsü, Sakarya.

[15] Fırat S., Cömert A.T. 2011. Uçucu Kül, Kireç ve Çimento ile İyileştirilmiş Kaolinde Kür Süresinin CBR Üzerine Etkileri. Gazi Üniversitesi Mühendislik Mimarlık Dergisi, 26 (4): 719730.

[16] Ünver E. 2015. Problemli Kil Zeminlerin Uçucu Kül ile İyileştirilmesi. Yüksek Lisans Tezi, Eskişehir Osmangazi Üniversitesi Fen Bilimleri Enstitüsü, Eskişehir.

[17] Bilici H., Okur D.V., Türköz M., Savaş H. 2018. Uçucu Kül Katkısının Meşelik Zemininin Kompaksiyon ve Dayanım Karakteristiklerine Etkisi. International Eurosian Conference on Science, Engineering and Technology(eurosianSciEnTech 2018), Ankara.

[18] Savaş H., Türköz M., Seyrek E., Ünver E. 2018. Comparison of the Effect of Using Class C and F Fly Ash on the Stabilization of Dispersive soils. Arabian Journal of Geosciences, 11: 612.

[19] O'Kelly B.C. 2008. Geo-engineering Properties of Granulated Blast Furnace Slag. International Conference on Geotechnical Engineering, Hammamet, Tunisia. 
[20] Cokca E., Yazici V., Ozaydin V. 2009. Stabilization of Expansive Clays Using Granulated Blast Furnace Slag (GBFS) and GBFS-cement. Geotechnical and Geological Engineering, 27: 489-499.

[21] Gör M., Aksoy H.S., Bilgen G. 2012. Farklı Katkı Malzemelerinin Kil Bir Zeminin Kıvam Limitleri Üzerinde Zamana Bağlı Etkisi. Ulusal Kil Sempozyumu, Niğde.

[22] Bilgen G., Kavak A., Çapar Ö.F. 2012 Düşük Plastisiteli Bir Kilde Katkı Olarak Çelikhane Cürufunun Kullanılması ve Kireç ile Etkileşimi. Karaelmas Fen ve Mühendislik Dergisi, 2 (2): 30-38.

[23] İncesu A.N. 2012. Düzenli Depolama Tesislerinde Kullanılmak Üzere Kum - Bentonit Karışımlarının Kireç ve Yüksek Fırın Cürufu Katkısı ile İyileştirilmesi. Yüksek Lisans Tezi, İstanbul Teknik Üniversitesi Fen Bilimleri Enstitüsü, İstanbul.

[24] Sivrikaya O., Yavascan S., Cecen E. 2014. Effects of Ground Granulated Blast-Furnace Slag on the İndex and Compaction Parameters of Clayey Soils. Acta Geotechnica, 1: 19-27.

[25] Yıldırım I.Z., Prezzi M. 2015. Geotechnical Properties of Fresh anda Ged Basic Oxygen Furnace Steel Slag. Journal of Materials in Civil Engineering, 27 (12): 1-11.

[26] Develioğlu İ., Pulat H.F. 2018. Yüksek Fırın Cürufunun Geoteknik Özellikleri ve Taşıma Kapasitesi Performansının İncelenmesi. Pamukkale Üniversitesi Mühendislik Bilim Dergisi, 24 (3): 433-438.

[27] Zorluer İ., Gücek S. 2017. Usage of Fly Ash and Waste Slime Boron for Soil Stabilization. Periodicals of Engineering and Natural Sciences, 5 (1): 51-54.

[28] Zorluer İ., Gücek S. 2014. The effects of Marble Dust and Fly Ash on Clay Soil. Sci. Eng. Compos Mater., 21 (1): 51-67.

[29] Zorluer İ., Demirbas A. 2013. Use of Marble dust and Fly Ash in Stabilization of Base Material. Sci. Eng. Compos Mater., 20 (1): 47-55.

[30] Yaghoubi E., Disfani M. M., Arulrajah A., Kodikara J. 2017. Impact of Compaction Method on Mechanical Characteristics of Unbound Granular Recycled Materials. Road Materials and Pavement Design, 15 (1) : 102-113. 